\title{
LEVANTAMENTO E ANÁLISE DA REDE VIÁRIA DO MUNICÍPIO DE PORTEIRINHA, MG POR MEIO DE IMAGEM WORLDVIEW - III E TÉCNICAS DE GEOPROCESSAMENTO
}

MAGALHÃES, Ivo Augusto Lopes ${ }^{1}$

PANIAGO, Yasmin Carvalho ${ }^{2}$

SANTOS, José Guilherme Rodrigues ${ }^{3}$

RESUMO: Objetivou-se com este estudo fazer o levantamento e analisar a rede viária do município de Porteirinha, MG, por meio de imagens do Satélite Wordview - 3 para fins de gerenciamento de rede. A metodologia consistiu na obtenção da imagem de alta resolução espacial do satélite Worldview - 3. Posteriormente criou-se um banco de dados geográfico por meio do aplicativo computacional SPRING 5.5.5, em seguida realizou-se o Processamento Digital de Imagem expresso na sequência metodológica: Mosaico, composição de bandas espectrais e fotointerpretação e vetorização do mapa de rede viária urbana. Como resultados obteve-se 3 imagens em composição falsa-cor e uma imagem em composição normal. A técnica de composição das bandas em falsa-cor das imagens do satélite Worldview - 3 não foi eficaz para a discriminação e levantamento da rede viária municipal, pois confundiu com outros alvos espectralmente semelhantes. A vetorização das ruas e nós foram possíveis, por meio da imagem processada, possibilitando a visualização dos objetos da edição gerando uma imagem vetorial totalizada em 1190 arcos e 715 nós, para toda a rede viária municipal. As imagens de alta resolução espacial do satélite Worldview - 3, por meio da técnica de composição de bandas em cor-normal demonstrou-se eficaz na identificação dos objetos que compõem a rede viária urbana, como sua discriminação, análise e quantificação. O uso de geotecnologias para desenvolvimento deste estudo permitiu a criação, interpretação e análise da rede viária no município de Porteirinha, MG, de maneira precisa, demonstrando ser uma alternativa viável e menos onerosa.

Palavras-chave: Fotogrametria. Sistema de Informações Geográficas. Geotecnologias.

\section{LANDING AND ANALYSIS OF THE ROAD NETWORK IN PORTEIRINHA, MG MUNICIPALITY BY IMAGE WORLDVIEW - III AND GEOPROCESSING TECHNIQUES}

\begin{abstract}
SUMMARY: The objective of this study was to survey and analyze the road network of the city of Porteirinha, MG, using images from the Satellite Wordview - 3 for network management purposes. The methodology consisted in obtained the high-resolution spatial image of the Worldview-3 satellite. Subsequently, a geographic database was created through the SPRING 5.5.5 computational application, followed by the Digital Image Processing expressed in the methodological sequence: Mosaic, composition of spectral bands and photointerpretation and vectorization of urban road network map. As results, 3 images were obtained in false-color composition and one image in normal composition. The technique of composing the false-color bands of the Worldview-3 satellite images was not effective for discriminating and surveying the municipal road network, since it confused with other spectrally similar targets. The vectorization of the streets and nodes was possible through the processed image, allowing the visualization of the objects of the edition, generating a vectorial image totaled in 1190 arcs and 715 nodes, for the entire municipal road network. The high-resolution images of the Worldview-3 satellite, using color-normal band composition, proved to be effective in identifying the objects that compose the urban road network, such as its discrimination, analysis and quantification. The use of geotechnologies for the development of this study allowed the creation, interpretation and analysis of the road network in the municipality of Porteirinha, MG, in a precise way, proving to be a viable alternative and less onerous.
\end{abstract}

Keywords: Photogrammetry. Geographic Information System. Geotechnology.

\footnotetext{
${ }^{1}$ Engenheiro Ambiental, mestre em sensoriamento remoto, Doutorando em Geografia, UNB.

${ }^{2}$ Estudante do curso de Geografia - UNB

${ }^{3}$ Engenheiro Ambiental - Faculdades Santo Agostinho, FASA
} 


\section{INTRODUÇÃO}

Atualmente no Brasil, ainda ocorre a ausência de planejamento estratégico municipal, notando-se que grande parte dos municípios de pequeno a médio porte não contém um Plano

Diretor elaborado. A falta dessas diretrizes municipais prejudica os planejamentos em diversos setores e projetos de expansões futuros (LOPES et al., 2017).

A falta dessas diretrizes, o crescimento populacional e a expansão territorial desenfreada prejudicam no planejamento das redes viárias, tornando-se dificultadas por problemas de gerenciamento e de gestão que são transmtidas para futuras administrações públicas.

Em municípios de pequeno, médio ou grande porte, a malha viária pode ser criada e administrada por meio de Sistema de Informação Geográfica- SIG e executado por sistemas de cartografia automática para redes técnicas, que são softwares específicos para cartografia digital, denominados AM/FM (automatic mapping), fornecendo, dados sobre rotas mais adequadas para atender coleta de resíduos sólidos, transporte coletivo e coleta seletiva (FITZ, 2008).

Ao se trabalhar com a criação da rede viária, depara-se com algumas técnicas que podem ser seguidas, como por exemplo, a fotointerpretação, que utiliza imagens de satélite ou ortofotos com intuito de identificar os objetos terrestres, traçamento de rotas e demilitação de áreas estratégicas de alvos georreferenciados por meio de SIG's. (MOREIRA, 2011).

O avanço da tecnologia de sistemas de informação geográfica evoluiu de maneira rápida a partir da década de 70. Este desenvolvimento foi originado por forte interesse comercial, mas não foi acompanhado por um correspondente avanço nas bases conceituais da geoinformação. Como resultado o aprendizado do Geoprocessamento tornou-se singularmente difícil. Ao oposto de outras disciplinas, não há um corpo básico de conceitos teóricos, que sirva de apoio para o aprendizado da tecnologia (FITZ, 2008).

Deste modo, a Ciência da Informação Espacial busca em seu desenvolvimento a utilização de técnicas para abstrair objetos para serem capazes de representar adequadamente fenômenos dinâmicos e menos oneroso para uma determinada região.

De maneira geral, o SIG consiste em um sistema digital para a aquisição, visualização, gerenciamento e análise de dados espaciais para propostas de planejamento e monitoramento do ambiente natural e sócio-econômico (ROCHA, 2007). Em se tratando de representação pictórica da localização georreferenciado e levantamentos preliminares de campo com SIG, pode-se realizar também delimitação de unidades-área, caracterização e análise de rede viária, promovendo a possibilidade de estabelecer novas alternativas de planejamento e gerenciamento municípal.

A proposta deste estudo faz juz sanar a falta de uma base de dados viária georrefecenciado do município de Porteirinha, MG, por meio de uma metodologia menos onerosa.

Diante do exposto, objetivou-se com este estudo, fazer o levantamento e análise da rede viária do município de Porteirinha/MG, por meio, de imagens do Satélite Wordview - 3 para fins de gerenciamento de rede.

\section{MATERIAL E MÉTODO}

\section{Caracterização da área de estudo}

O município de Porteirinha tem a população estimada em 38.709 habitantes, com área da unidade territorial de 1.749,683 $\mathrm{Km}^{2}$, localiza-se na microrregião de Janaúba, MG com localização geográfica na latitude $15^{\circ} 44^{\prime} 38^{\prime \prime} \mathrm{S}$ e longitude $43^{\circ} 1^{\prime} 29^{\prime \prime}$ O. (Figura 1 ). 
A temperatura média do municípal é de $27^{\circ} \mathrm{C}$, com registro de máxima de $38^{\circ} \mathrm{C}$ e mínima de $18^{\circ} \mathrm{C}$. O clima da cidade é considerado como mesotérmico, devido a altitude que também é sinônimo de boa umidade e com duas estações bem definidas: verão e inverno.

A precipitação média anual de $800 \mathrm{~mm}$, se concentra nos meses de outubro, novembro, dezembro, janeiro, fevereiro e março. O município de Porteirinha tem a extensão de $1.749,68 \mathrm{Km}^{2}$, assim apresenta um relevo topográfico de forma bem diversificada, onde $40 \%$ da área de seu solo é plano, $50 \%$ apresentase ondulado e $10 \%$ é do tipo montanhoso, registrando sua altitude máxima de 1.544 metros no morro do preto e a altura mínima de 465 metros próximo da lagoa cachoeira em relação ao nível do mar IBGE (2014).

Figura 1 - Localização geográfica do município de Porteirinha, MG.

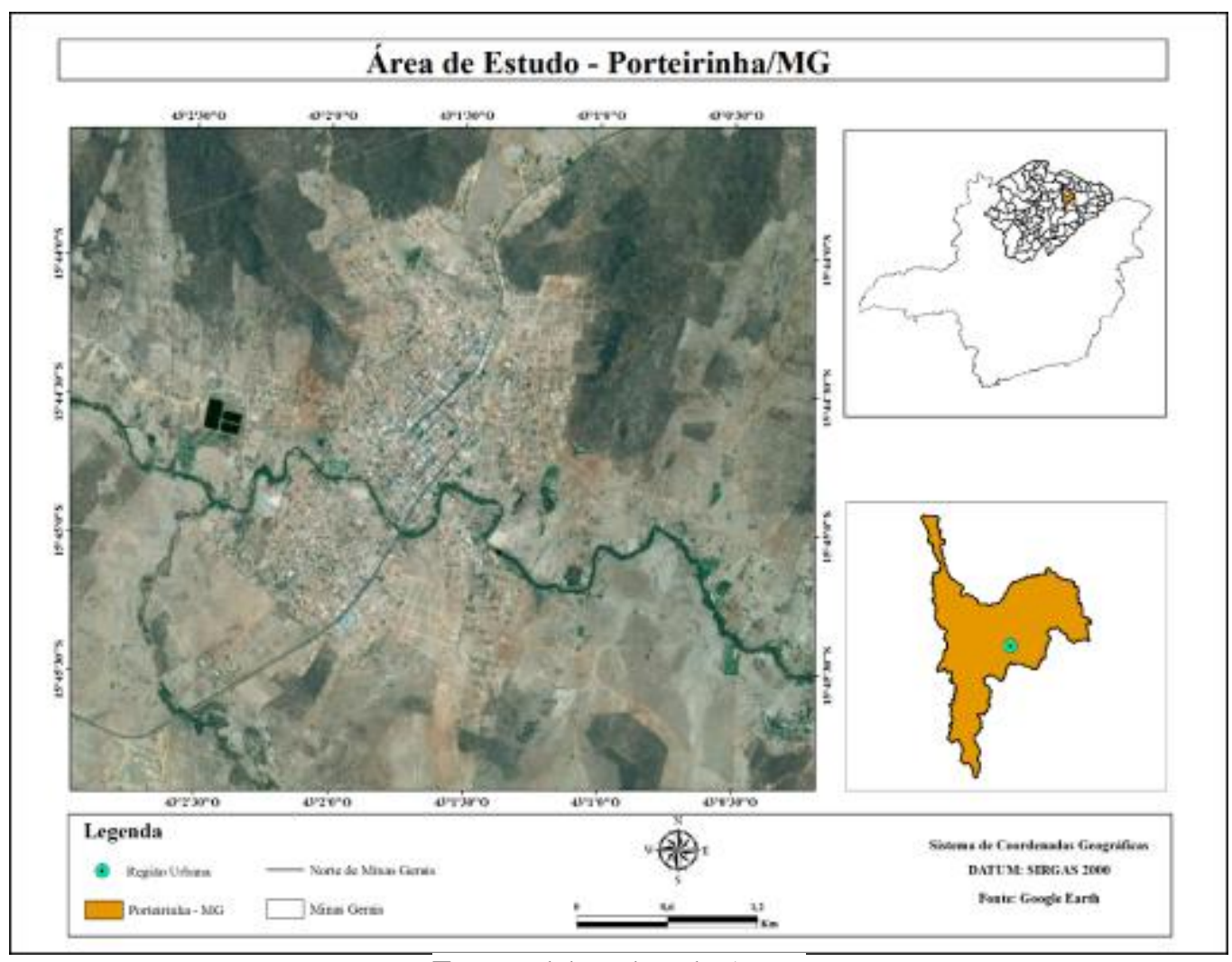

Fonte: Elaborado pelo Autor.

\section{Elaboração do banco de dados}

Utilizou-se o Sistema de Processamento de Informações Georreferenciadas - SPRING 5.5.5 (Câmara et al., 1996), que é um software gratuito, desenvolvido pela Divisão de Processamento de Imagens - DPI do INPE e que possui funções de processamento digital de imagens dentre outros técnicas para a criação do banco de dados geográficos (INPE, 2011),

A projeção utilizada para criação do banco de dados foi a Universal Transverso de Mercator UTM com sistema de projeção geográfica (LAT-LONG) e Datum de referência (SIRGAS 2000). Após a ativação do banco de dados elaborou-se os planos de informações -PI das categorias: cadastral, temático e imagem.

Utlizou-se o software ArcGis 10.4, em sua execução do banco de dados na extensão arccatalog e criou-se um novo arquivo shapefile do tipo linha e ponto, para gerar a malha de vetorização e a carta 
imagem da rede viária do município de Porteirinha.

\section{Processamento Digital de imagem - PDI}

As imagens utilizadas para elaboração deste estudo foram obtidas por meio do satélite Worldview - 3. A imagem possui alta resolução espectral, temporal e espacial, com capaciadade de capturar alvos com tamanhos superiores a 2,50 metros no terreno.

As imagens adquiridas para a execução do trabalho, foi executado pelo processo de mosaico de imagens por meio do software ENVI 5.0.

As imagens adquiridas por sensores eletrônicos, em diferentes bandas, são originalmente produzidas de forma individual preto e branco, por satélites, por fotografias ou, ainda, por scanners, assim ao se projetar e sobrepor essas imagens, através de filtros coloridos azul, verde e vermelho (cores primárias), é possível gerar imagens coloridas (FLORENZANO, 2011), conforme a figura 2. Neste estudo realizou-se a composição entre bandas Azul, Verde e Vermelho para obtenção da imagem em composição colorida

Esta composição entre bandas de imagens permite a execução e criação de imagens virtuais da área para a realização de um posterior cruzamento das informações obtidas, ou até mesmo para a elaboração de mapas temáticos (FITZ, 2008).

Figura 2: Processo de composição coloridas das bandas utilizando as cores primárias RGB.

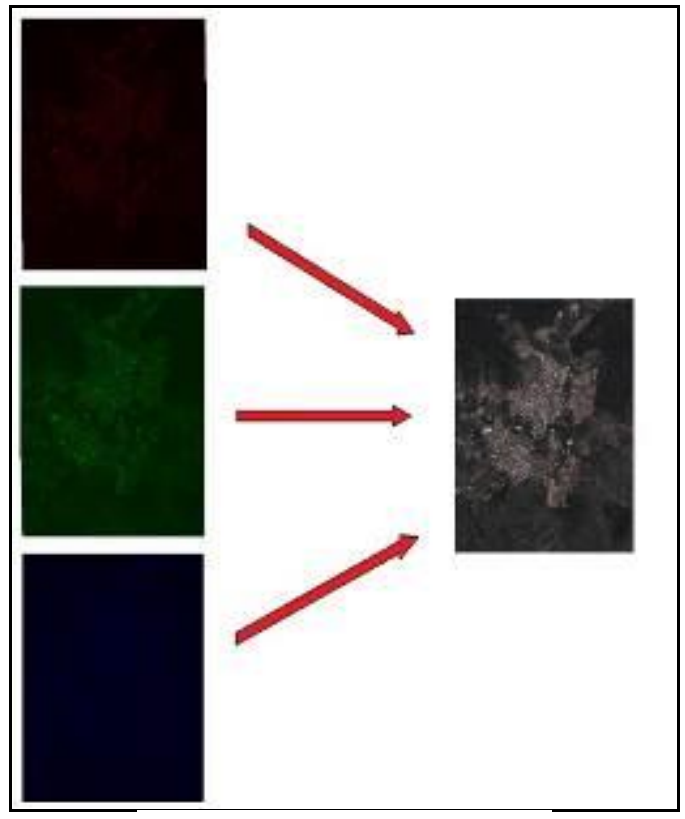

Fonte: Elaborado pelo Autor.

\section{Fotointerpretação e vetorização da rede viária}

Aplicou-se o processo de fotointerpretação em tela na escala cartográfica de trabalho de 1:400. Identificou-se a localização precisa das ruas, estradas e cruzamentos para o município de Porteirtinha, MG. Posteriormente após a fotointerpretação converteu-se a carta imagem do formato matricial para o vetorial com intuito de extração apenas da rede viária. Essas técnicas foram realizadas por meio do software ArcGis 10.4, aplicados a carta imagem, pela ferramenta de edição, dessa maneira gerou-se um novo arquivo shapefile de linhas vetoriais e pontos conforme esquematiza a Figura 3. 
Figura 3: Processo de vetorização por diagrama de blocos para vetorização da rede viária.

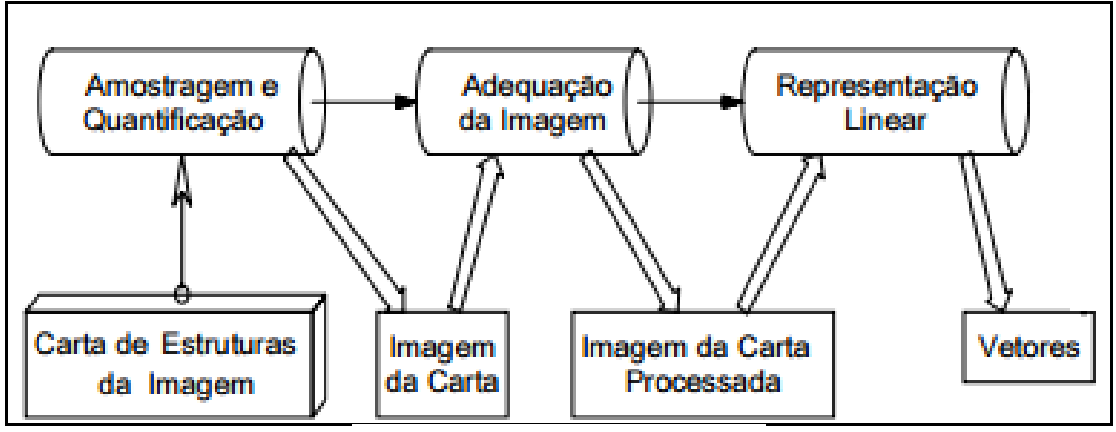

Fonte: Elaborado pelo Autor.

Os procedimentos metodológicos realizados para levantamento e análise da rede viária municipal da área urbana do município de Porteirinha, MG, estão sintetizados conforme o fluxograma da Figura 4.

Figura 4: Fluxograma metodológico representativo das etapas realizadas para desenvolvimento do estudo.

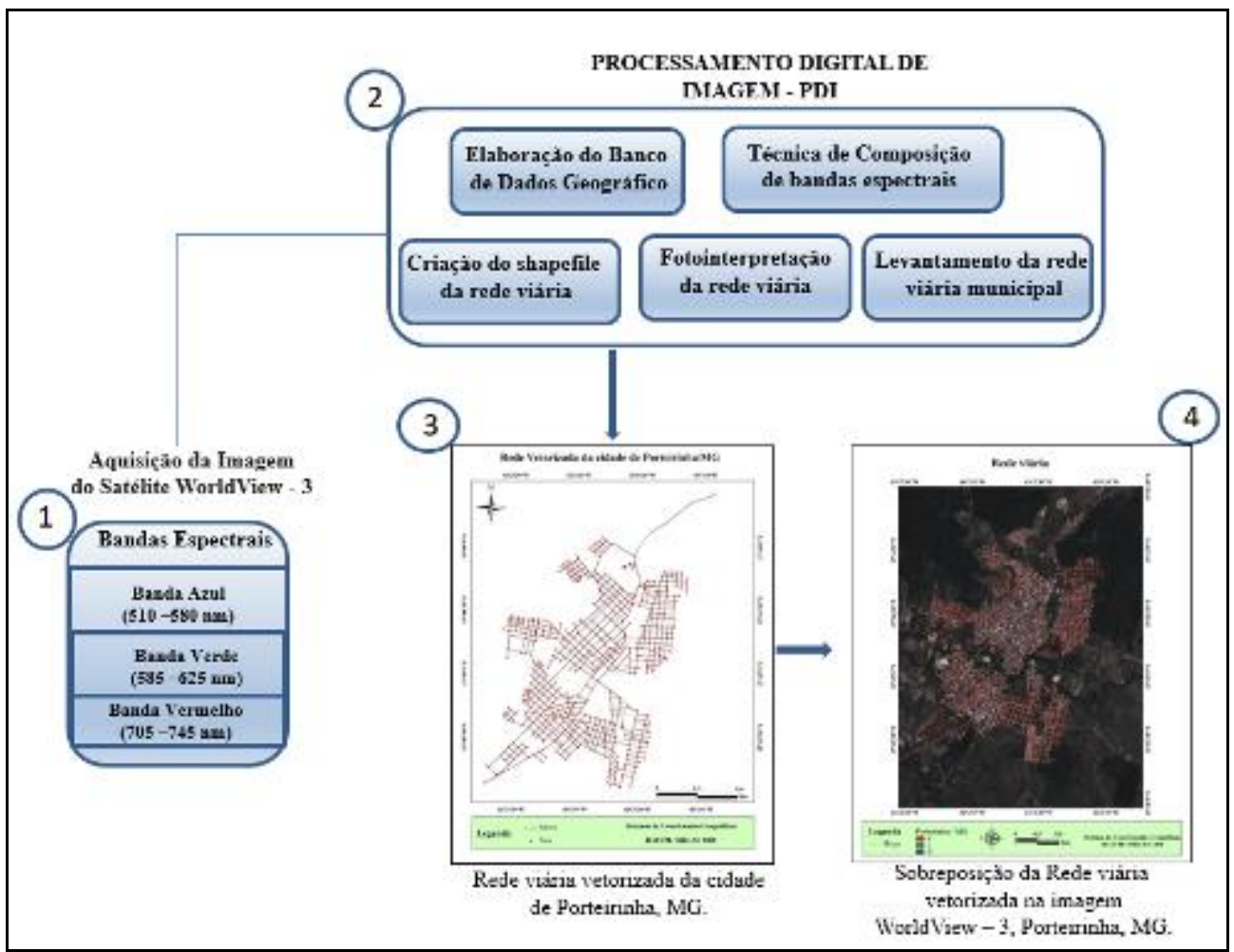

Fonte: Elaborado pelo Autor.

\section{RESULTADO E DISCUSSÃO}

\section{Interpretação e caracterização da imagem}

O conjunto de metodologias e ferramentas utilizadas, como a imagem do satélite Worldview -3 , permitiu utilizar técnicas da composição de bandas com o auxílio do processo de cores aditivas RGB, foi obtido 4 imagens coloridas para a região em estudo. Comprovou-se poder analisar as imagens amostrais contemplando diferentes combinações de bandas, como as imagens "falsa-cor" que apresentam cores diferentes da combinação das cores do visível, assim a Figura 4 que utiliza as bandas 2 "R", banda 3 "G" e 
banda 1 "B", realça as características como a vegetação em tons avermelhados e o solo exposto e a área urbanizada estão com tons branco - amarelado.

Nobrega (2007), corrobora com este estudo ao afirmar que a composição de bandas espectrais e o uso combinado desses componentes de imagem permite uma melhor discriminação tanto das áreas com superfícies antropizadas, quanto as de vegetação, que deram auxilio a detecção das vias da rede viária.

Notou-se por meio da figura 5, uma maior dificuldade para identificar visualmente a rede viária na área em estudo, pois a dicriminação para apenas essa classe torna-se mais imperceptível pois existe diversos alvos de edificações e construção urbana com a resposta espectral semelhante a rede viária, dessa maneira, contribuiu para a confusão da distinção da rede viária na imagem.

Figura 5: Imagem Worldview - 3 na composição falsa-cor, Bandas 2R, 3G e 1B.

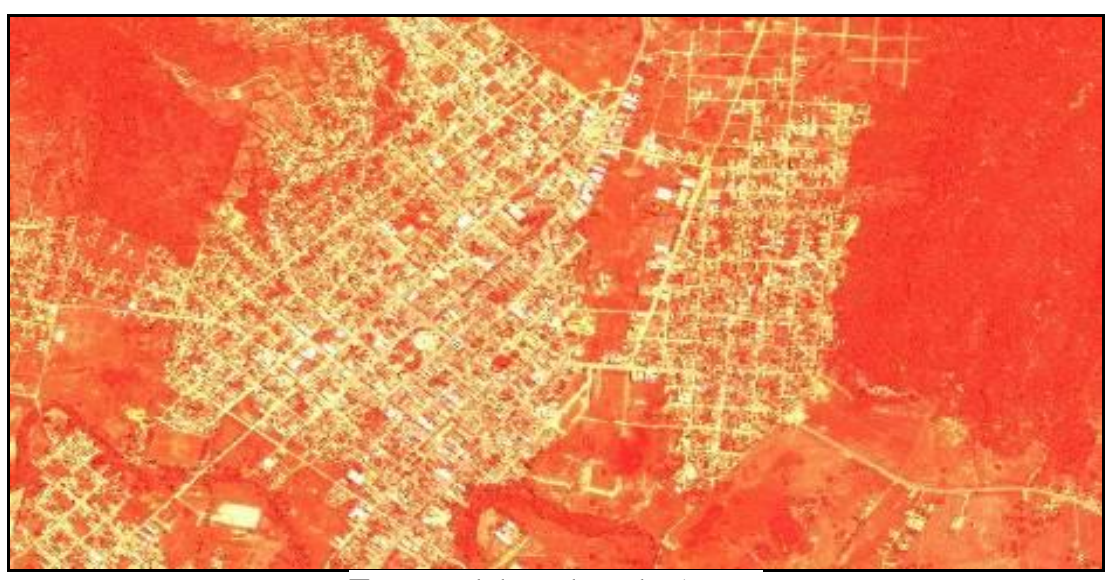

Fonte: Elaborado pelo Autor.

Já a combinação de imagem "falsa-cor", com a composição de bandas de na sequência banda 3 na cor "R", banda 1 na cor "G" e banda 2 na cor "B", obteve uma resposta espectral da área urbana em tom de branco, a vegetação na cor verde e o solo exposto e ruas sem pavimento a cor amarela. Também observou-se uma confusão espectral para esses alvos, tornando-se dificil a identificação somente da rede viária. Figura 6.

Figura 6: Imagem Worldview - 3 na composição falsa cor, bandas 3R, $1 \mathrm{G}$ e 2B.

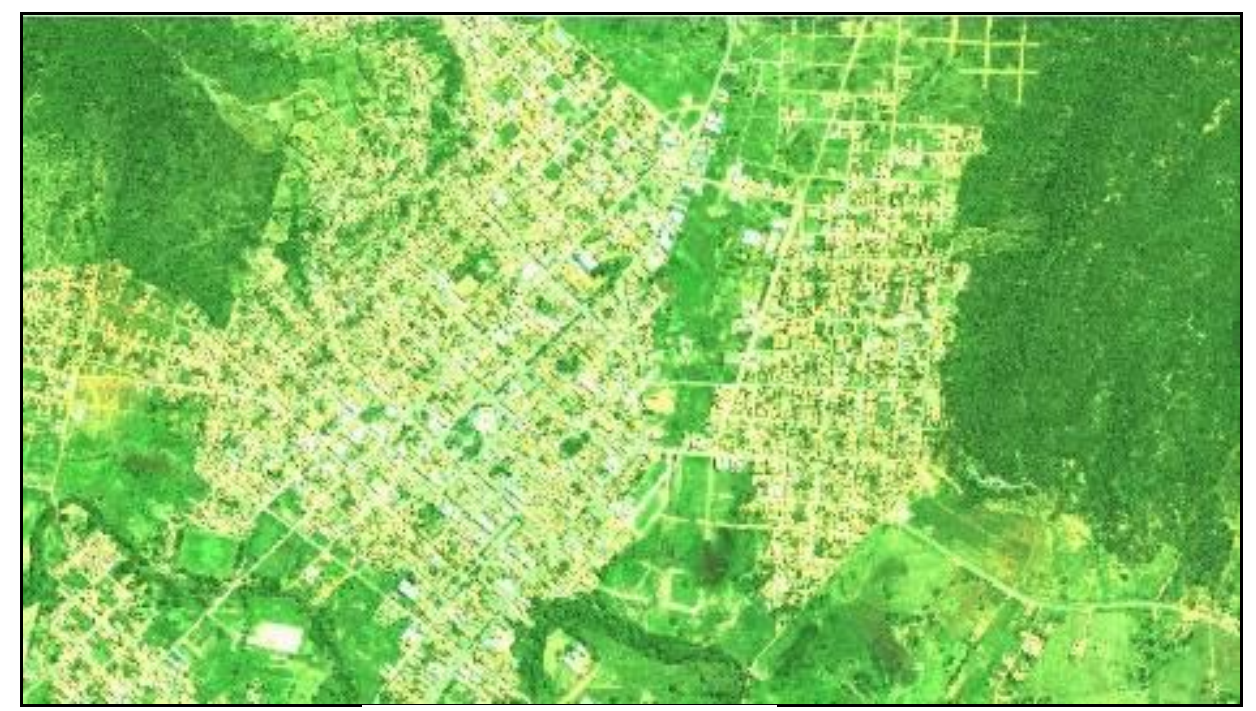

Fonte: Elaborado pelo Autor. 
A próxima imagem "falsa-cor" apresenta a combinação de bandas como a banda 2 na cor "R", banda 1 na cor "G" e banda 3 na cor "B", já identificado as tonalidades de cores como a vegetação com a cor azul - violeta e a área urbana e solo exposto com na cor branca com resquícios em tons de laranja, compreendendo que a rede viária ainda sim, aparenta a mesma cor das edificações do meio urbano, conforme a Figura 7. As composições das bandas falsa-cor nestas sequencias analisadas não demostraram ser apropriadas para análise apenas da rede viária municipal.

Figura 7: Imagem Worldview - 3 na composição Amostra de combinação falsa-cor, 2R, 1G e 3B.

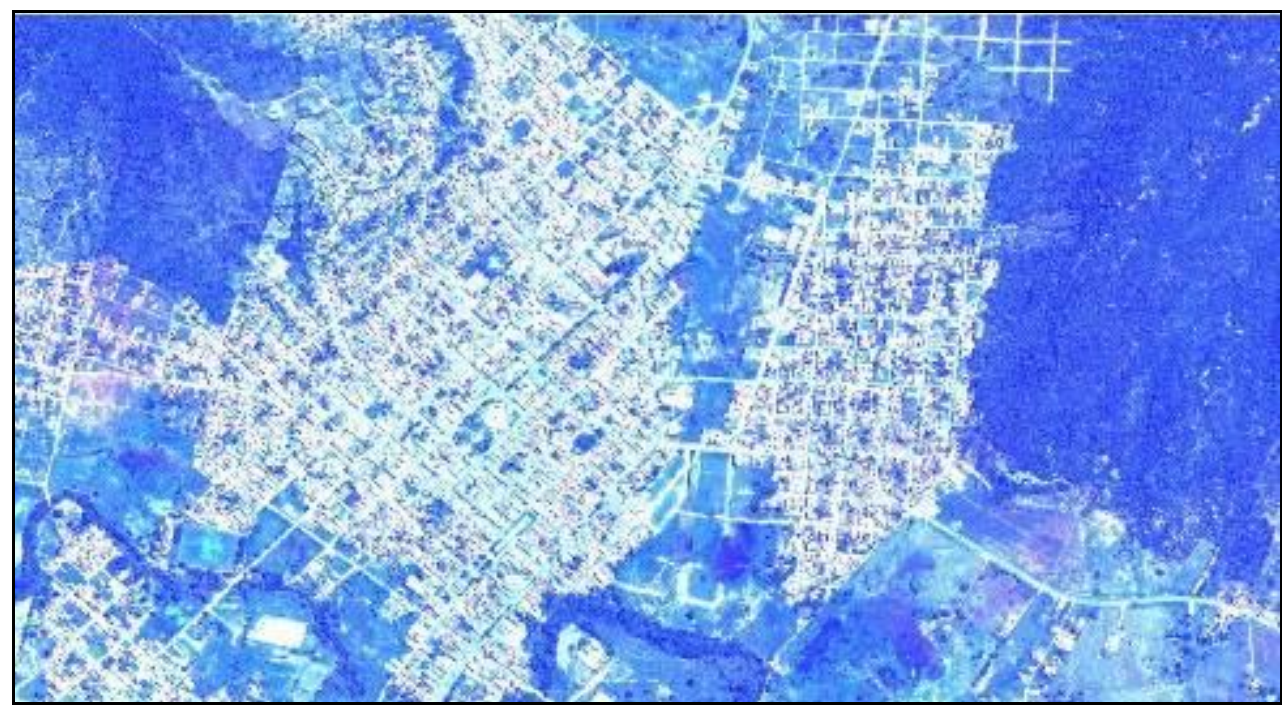

Fonte: Elaborado pelo Autor.

Já para a imagem em composição normal banda 3 na cor "R", banda 2 na cor "G" e banda 1 na cor "B" obteve-se o melhor resultado para discriminação e interpretação da rede viária urbana para fins de vetorização das ruas, pois por meio deste resultado visual e das respostas espectrais dos alvos inseridos no município obteve-se uma maior nitidez para visualização das ruas, logradouros e estradas tornaram-se a fotointerpretação mais precisa. Figura 8.

Figura 8: Imagem Worldview - 3 na composição colorida-cor, 3R, 2G e 1B.

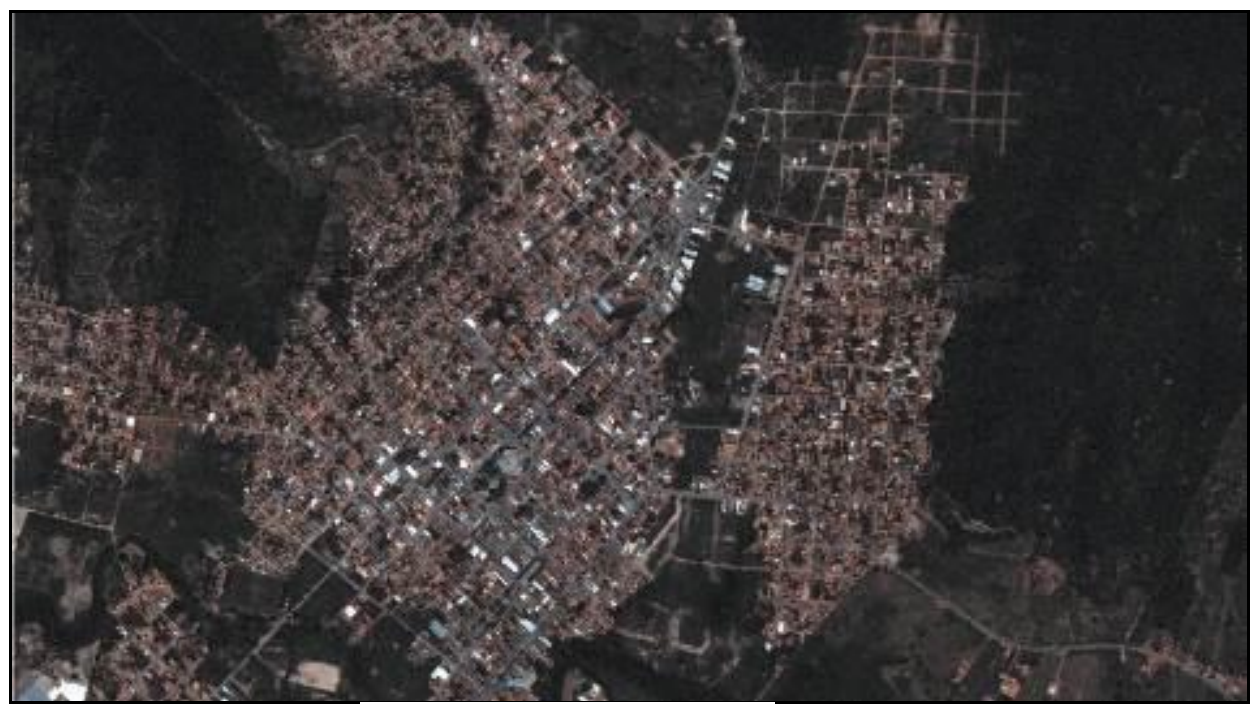

Fonte: Elaborado pelo Autor. 
Vale ressaltar que um dos fatores diferenciais para a fotointerpretação dos alvos na área em estudo foi o fato que a imagem de alta de resolução espacial, possui uma visibilidade dos objetos, tornando-se fundamnetal para esse tipo de análise.

Assim comprovou-se que por meio das técnicas de comparação e composição de bandas a trasncrição do meio físico para meio computacional todas as feições, permitindo assim a interpretar a imagem que representa toda a área urbana da cidade de Porteirinha, MG que possui os alvos com igual e maior resolução espacial para a rede viária da área urbana da cidade.

\section{Análise da Rede viária}

O processo de vetorização da rede viária foi realizado, por meio do software ArcGis 10.4 que possui ferramentas como a Edição, que permite criar feições como linhas e pontos que podem ser empregados como ruas ou logradouros e nós, para serem usados em estudos de redes.

Deste modo a vetorização das ruas e nós foram possíveis, por meio da imagem processada anteriormente, possibilitando a visualização dos objetos da edição gerando uma imagem vetorial totalizada em 1190 arcos e 715 nós, para toda a rede viária municipal, conforme a Figura 9.

Figura 9: Rede viária vetorizada da cidade de Porteirinha, $M G$ por meio de arcos e nós.

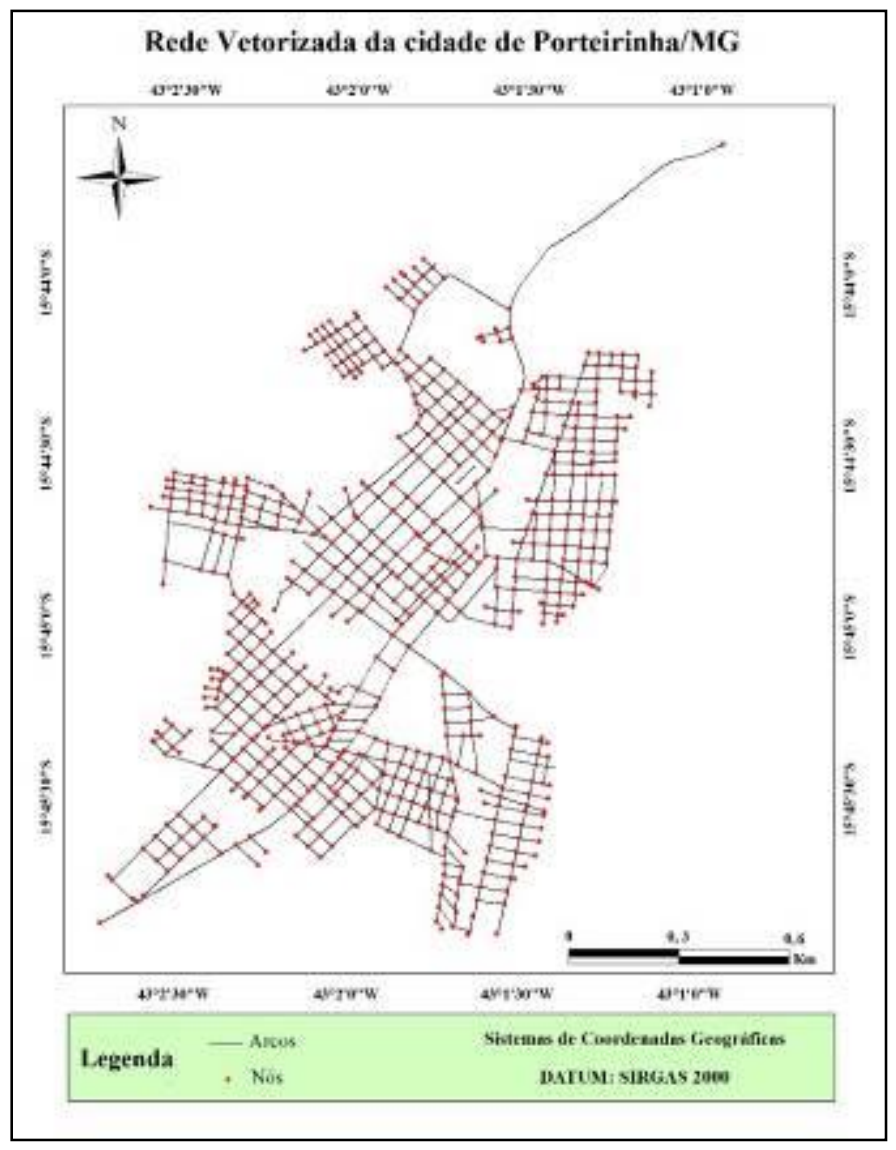

Fonte: Elaborado pelo Autor.

Os estudos de redes abrangem desde quantificação de ruas ou interseções, até os métodos de roteirização seja ela de coleta de resíduos sólidos, seletiva, linhas de transporte coletivo e os nós por sua vez como ponto de referência para cruzamentos de tubulações de água ou esgoto ou de redes elétricas. 
A partir da rede viária criada, foi analisada as linhas e nós criados, com intuito de aplicação em outros processos analíticos e de gestão no banco de dados geográfico com a finalidade de gerar novos produtos.

Portanto a partir da teoria dos grafos e o complemento do facility management podemos analisar a viabilidade da rede criada, a ser usada para gerar outro produto como exemplo a roteirização de coleta de resíduos sólidos. Logo a teoria dos grafos tem como base de todo seu planejamento as linhas e pontos que são denominados como arcos e nós, isso possibilita que ao se planejar o tipo de rede o sistema utilizará estas informações para serem convertidas em resultados para criação de rotas, conforme a Figura 19.

A partir disso o facility management vinculado ao sistema de rede viária vem acrescentar a questão do planejamento se subdivide-se em estratégia, recursos, operação, revisão e desenvolvimento contínuo. Deste modo a estratégia significa qual modelo de vai ser utilizado seja ele de coleta de resíduos sólidos, coleta seletiva, transporte coletivo e dentre outras, os recursos a serem utilizadas poderão adentrar sobre financeiros e informações sobre a rede, a operação define-se a qual tipo pode ser utilizada como modelos empíricos ou matemáticos, após todo esse planejamento se faz jus uma revisão dos processos adicionados a aplicação e pôr fim executa o projeto visando seu desenvolvimento contínuo.

Figura 9: Sobreposição da Rede viária vetorizada na imagem Worldview - 3 da cidade de Porteirinha, MG.

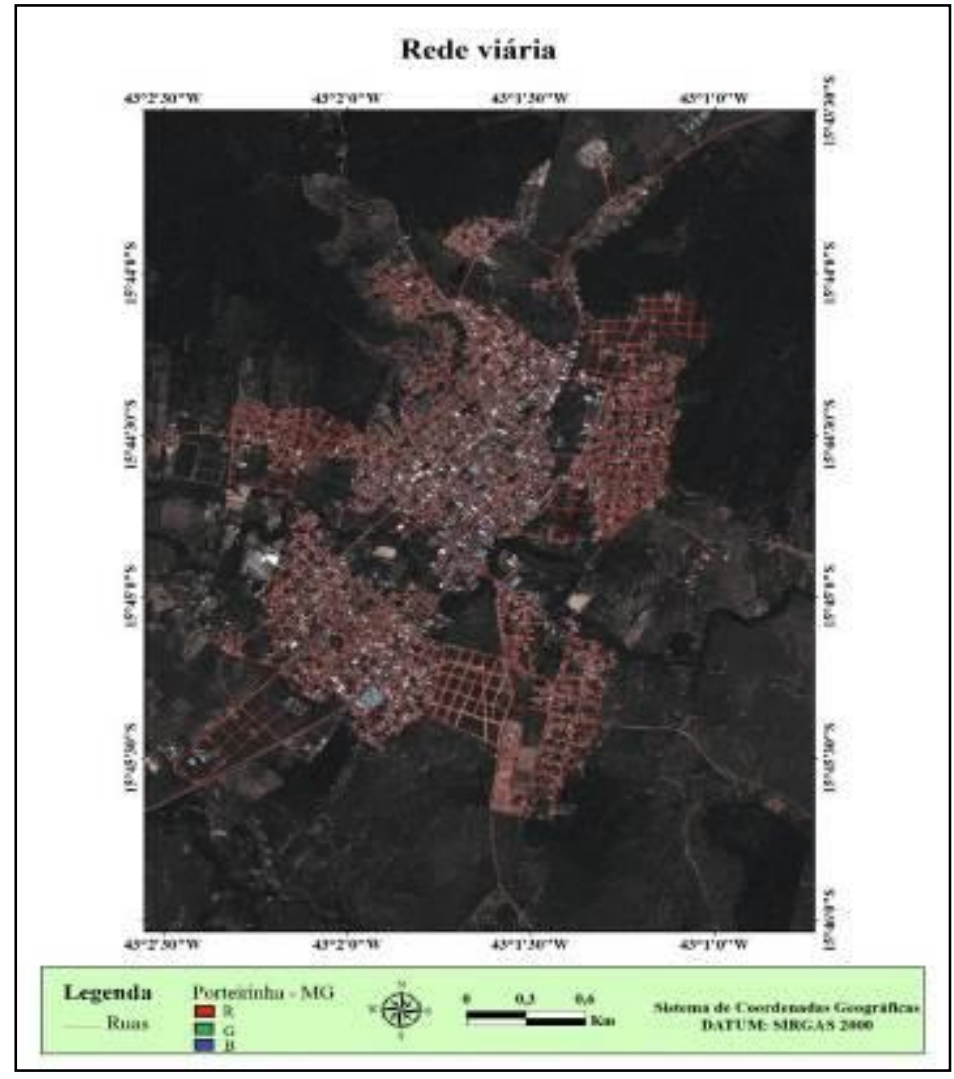

Fonte: Elaborado pelo Autor.

\section{CONCLUSÃO}

O uso de geotecnologias para desenvolvimento deste estudo permitiu a criação, interpretação e análise da rede viária no município de Porteirinha, MG, de maneira precisa e eficaz, demonstrando ser uma alternativa viável e menos onerosa. 
As imagens de alta resolução espacial do satélite Worldview - 3, por meio da técnica de composição de bandas em cor-normal demonstrou-se eficaz na identificação dos objetos que compõem a rede viária urbana, como sua discrimanação, análise e quantificação.

A técnica de composição das bandas em falsa-cor das imagens do satélite Worldview - 3 não foi eficaz para a discriminação e levantamento da rede viária municipal, pois confundiu com outros alvos espectralmente semelhantes.

O levantamento e a criação da rede viária municipal poderá ser útil para o desenvolvimento municipal de futuros projetos, tendo em vista que os resultados expressos em arquivos vetorias poderá compos o banco de dados geográfico da prefeitura municipal.

Por fim, ressalta-se que o estudo realizado demonstra o uso de geotecnologias para auxiliar em projetos de redes, visando o planejamento da gestão seja ela de um município, bairro ou outras áreas, tornando uma ferramenta de fácil manuseio e que é claramente de baixo custo e rápido processamento.

\section{REFERÊNCIAS}

CÂMARA, G. et al. SPRING: Integrating Remote Sensing and GIS with Object-Oriented Data Modelling. Computers and Graphics, vol.15, n.6, p. 395-403, 1996.

ESRI. Disponível em: http://www.esri.com/software/arcgis/arcgis-for-desktop. Acesso em: 14 jul. 2018.

FITZ. P, R. Geoprocessamento sem complicação. Porto Alegre: Oficina de textos.,. p. 160, 2008.

FLORENZANO, T.G. Iniciação em Sensoriamento Remoto. 3 ed. São Paulo: Oficina de texto, São Paulo, SP. 2011. p. 128.

Ibge- Instituto Brasileiro de Geografia e Estatística, 2014. Disponível em: < http://www.cidades.ibge.gov.br/painel/painel.php?lang=\&codmun=315220\&search=minasgerais\%7Cporteirinha\%7Cinfograficos:-dados-gerais-do-municipio>. Acesso em: 18 maio 2018.

INPE- Instituto Nacional de Pesquisas Espaciais. Disponível em: $\underline{\text { www.inpe.br }}$ Acesso em: 16 maio 2018.

LOPES, W. G. R. Et al. Reflexões sobre o Plano Diretor como instrumento de gestão em municípios brasileiros. GeoUERJ. V. 1. p, 145-168. 2017.

MOREIRA, M. A. Fundamentos do sensoriamento remoto e metodologias de aplicação. 4 ed. Viçosa: UFV, 2011. p. 422.

NATIONAL RESEARCH COUNCIL. Rediscovering Geography: New Relevance for Science and Society. National Academy Press, Washington, DC. p. 248, 1997.

NÓBREGA, R. A. A. Detecção da malha viária na periferia urbana de São Paulo utilizando imagens de alta resolução espacial e classificação orientada a objetos. 2007. 162 f. Tese (Doutorado em Engenharia Civil) - Universidade de São Paulo - UPS, São Paulo, 2007.

ROCHA, C.H.B. Geoprocessamento: Tecnologia interdisciplinar. Juiz de Fora: Ed do Acta, 2007. p. 109

SULSOFT, Disponível em: < http://www.envi.com.br/>Acesso em: 9 nov. 2015. 